\title{
NAVIGATING AMBIGUITY: DISTRIBUTIVE AND INTEGRATIVE NEGOTIATION TACTICS IN CHINA
}

\author{
Barthelmess, P.Y., Enzmann, P., Settelen, M., Schärmeli, N.
}

People usually view negotiations as either an integrative process in which both sides can gain (win-win) or a distributive struggle in which one side wins and the other loses (winlose). Culture affects how people conduct negotiations, and the Chinese people can rely on a long civilizational tradition of both - highly refined integrative as well as smart and ruthless distributive negotiation styles. The coexistence of both styles may lead to ambiguous negotiation situations. The purpose of this study is to explore whether the relationship relevance influences the Chinese people's choice of negotiation style. We investigated the research question by conducting ten in-depth interviews among European executives with long-term experience in China and analyzed the content of the transcripts by deductively building qualitative categories. The findings indicate that high relationship relevance influences the Chinese negotiation style towards a more collaborative integrative approach. By focusing on the relationship aspect of negotiations, we aim to contribute towards better understanding in an under researched field of relationship's impact on negotiation.

Keywords: Integrative bargaining; distributive bargaining; negotiation tactics; Chinese negotiation; Chinese negotiation principles

JEL Classification: F23, F51, Z1

\section{Introduction}

Chinese negotiators are influenced by their cultural traditions and immediate context (Phatak \& Habib, 1996). Their negotiating style originates from a complex mixture of traditional culture, most importantly Confucianism, but also the so-called War Stratagems (Sun Tzu's "Art of War" or the "36 Stratagems" are the most renowned works) and, according to Sebenius \& Qian (2008, p. 6), in recent times the so-called Guo Qing - "the milieu in which Chinese business culture evolved." This includes features such as a centrally controlled political system, multi-layered business governance, the possibility of fast socio-economic advancement, and a general lack of regulatory transparency. This diverse blend creates a distinct negotiating style defined as "contradictory" (Pye, 1992) and "a strange mix" (Tian, 2016, p.169), differing "in many ways from those that are 
found in business negotiations in other parts of the world" (Tian, 2016, p.169; see also Salacuse, 2003).

In this study, we explored whether the relevance one attributes in building relationship with the Chinese influences the choice of negotiation style on the Chinese side. For this, we have identified four topics relevant in negotiations: time management, hospitality, communication style, and dealing with practical constraints such as red tape, and intransparent and ambiguous rules and regulations. We considered the negotiators' experiences from two different positions, namely from a high and low relationship relevance standpoint. We studied the research question strictly qualitatively by conducting ten in-depth interviews with European executives who have extensive negotiation experience in China. We investigated the content of the transcripts by constructing the coding table (cf. Appendix) deductively, i.e., based on the literature review, and performed the analysis steps suggested by Mayring (2000). By focusing on relationships and negotiation style, we aim to make a research contribution on a topic "insufficiently studied" in recent decades (Cheng et al., 2017).

Beginning with an introduction to the theoretical concepts of integrative and distributive negotiation behavior, and its correspondence to Chinese cultural heritage, we introduce the Chinese concepts and implicit understanding of relationship, trust, and deception, followed by a literature review on the four above mentioned exemplary topics (time, hospitality, communication style, and practical constraints such as red tape, intransparent and ambiguous rules and regulations). After that, we introduce the methodology applied followed by the findings section, where we identify two groups: Group 1, which attributes high relevance to relationship building and Group 2, which attributes low relevance to it. Afterward, for each group separately, we illustrate how they experienced the Chinese negotiation style for the four previously identified topics. We conclude with a discussion and a description of the practical implications.

\section{Theoretical Framework}

\subsection{An Ambiguous Take on Negotiations}

Negotiation seems to suggest a world of opposites by employing methods which emphasize both "soft" and "hard" approaches. These are reflected in the concepts of integrative and distributive negotiation based on the framework provided by Walton and McKersie (1965) and also evident in Chinese negotiation (Fang, 2006).

The "soft" integrative approach to negotiation allows both sides to achieve their goals. During negotiations, both parties divulge their interests to find solutions that reconcile their respective interests (win-win). Whether or not both parties achieve their stated goals depends on the free flow of information and an emphatic willingness to understand each other's real needs and objectives (Lewicki et al., 2015). 
Confucianism as a tradition corresponds well to the integrative negotiation style since it focuses on interpersonal relationships by emphasizing values such as loyalty, reciprocity, social responsibility, group orientation, and group identity. Relationships are always tied to reciprocal obligations, multi-functional in their utility, and part of a network (Yao, 2000). In this sense, personal relationships either substitute or provide stability in the complex, sometimes opaque and arbitrary, Chinese business environment (Vanhonacker, 2004). The Confucian negotiator is not only sincere and well-mannered but, more importantly, interested in a long-term relationship (Vanhonacker, 2004). Consequently, it can be assumed that if one manages to gain the trust of a Confucian negotiator, it is likely that the resulting contract will satisfy both parties and create a win-win framework (Sebenius \& Qian, 2008). In this sense, the Confucian negotiator operates from an integrative bargaining position.

In contrast to the reconciling integrative approach, the distributive negotiation assumes conflicting goals originating from existing limited resources, hence one party's gain means the other party's loss (win-lose). The setup is inherently competitive since both parties strive to maximize their share. Goals are achieved depending on the tactics employed, examples of which include: opening offers, assessing, managing, and modifying the other negotiating party's targets and points of resistance. There is a focus on the development of options and market awareness to help negotiators avoid poor decisions and achieve the best outcome for themselves. Manipulating the information flow or applying time pressure are examples of tactics typical of this method of negotiation (Lewicki et al., 2015).

Within Chinese tradition, war stratagems mirror the distributive negotiation approach as they emphasize the importance of winning in a battle-like scenario. Sun Tzu's "The Art of War" (6th Century BCE) and its doctrine that all warfare is based on deception, as well as "The 36 Stratagems", a collection of suggested actions first referenced in 500 CE and fully compiled in 1600 by an unknown author, are the two best known works in this context (for "The 36 Stratagems," see von Senger, 2004). A tactical negotiator regards the marketplace as a battlefield and interprets negotiations from a win or lose perspective (Fang, 2006). The goal is to outwit the opponent with the help of 36 stratagems that teach the art of deception, trickery, and cunning - all in the pursuit of victory. Chinese deception can be well disguised (Stratagem 10: "Hiding the dagger behind a smile."), deceive the opponent with something that does not exist in reality (Stratagem 29: "Decorating a [barren] tree with [artificial] flowers.”), or exploit individual weaknesses (Stratagem 31: "Use beautiful women [to corrupt the opponent].").

The element of deception, defined by Murninghan as a "deliberate act taken by one party with the intention of creating or adding support to a false belief in another party," is not absent in any negotiation setting with the Chinese (Murninghan et al., 1999, p. 2). As the collection of war stratagems show, the Chinese can rely on a long and refined tradition of the art of deception, trickery, and cunning behavior (see above). According to Zhang (2015), Confucian tradition however, also has a rather high, inherent tolerance level 
towards deception; due to the importance of maintaining harmony and face, conflict is not revealed openly. In case of disagreement or an unwelcome turn of events, an excuse needs to be invented and a third party blamed. In this case a lie or a trick serves the purpose to maintain harmony between the negotiating parties as well as keeping face. In addition, the importance of group loyalty means that deceiving the "other" side in favor of one's own group has the effect of distancing the deceiver from a moral responsibility towards truthfulness (Triandis et al., 2001).

Negotiators face the dilemma of working cooperatively in an integrative setting by, for example, truthfully and openly sharing information about their preferences and encouraging their counterparts to do the same in order to increase the mutual satisfaction i.e., "enlarging the pie" (Kong et al., 2014, p. 1235; Lax \& Sebenius, 1986). On the other hand, negotiators must recognize that the other side may use a distributive approach by "slicing the pie" (Kong et al., 2014). Integrative behavior is inherently risky since a cooperative approach by one side can be exploited by the other. In this sense, a critical distinction between integrative or distributive bargaining behavior is the extent to which it makes the negotiator vulnerable and ready to accept risk. In this context, Kong et al. (2014) argues that the level of trust is negatively correlated to the level of risk. If the counterpart is trusted, social exchange theory would predict the willingness to engage in a particular behavior because it can be expected that this behavior will be reciprocated, which in turn lowers risk and ultimately yields benefits. Hence, trust increases integrative behavior and decreases distributive behavior (see also Butler, 1999; Gunia et al., 2011).

The level of trust in the Chinese context is related to an accumulation of positive experiences from the past and the prospect of mutually beneficial future cooperation (Leung et al., 2011). An accumulation of positive experiences as well as the expectation of the continuation of fruitful collaboration creates a trust which grows on the basis of a healthy interpersonal relationship and eventually leads to a so-called "old friend" relational status with access to a wider system of relationships and reciprocal obligations (guanxinetwork; definition derived from Seligman, 1999) (Leung et al., 2011). Access to this interpersonal relationship network transforms both negotiating parties.Although once separated into two different groups,the merge into one unified group decreases moral acceptance of deception on the part of the Chinese.

\subsection{Negotiating in China}

China's rapid economic development has incited substantial interest from managers and scholars alike on how to navigate the country's business environment successfully. Among the prominently discussed topics is what to consider when negotiating with the Chinese. A literature review reveals that topics which contribute to an understanding of the issue can be broadly grouped into topics related to time, hospitality, neutral and affective communication, and the handling of practical constraints, such as red tape and intransparent and ambiguous rules and regulations. These groups serve to guide our 
deductively derived study. The groups are considered from Confucian cultural tradition respectively as tactical negotiation tools (cf. for an overview appendix 1). For the latter, we also used literature stemming from the Chinese war stratagem tradition. The importance and role of relationship in negotiations will be treated separately and later connected to the four groups.

\section{Relationship}

Developing a wide relationship network (guanxi 关系) in China used to be crucial in business interactions as an important means of making things happen (Buttery \& Leung, 1998). In ancient times and even today, relationships provide support in uncertain environments and ensure mutual and reciprocal understanding in the event of difficulties. This relationship is connected to Confucian thought, as are the concepts of exchanged favors (renqing 人情), giving face (mianzi 面子), as well as hierarchy and the consequent responsibilities and rights connected to one's hierarchical position (li 礼) (Buttery \& Leung, 1998).

Due to its long-term character, trust becomes the foundation of relationships since favors are not necessarily returned immediately. Business is conducted between parties that trust each other mutually. Without trust, a contract cannot be signed (Ghauri \& Fang, 2000; Sebenius \& Qian, 2008). Having good relationships with officials can make a difference to how quickly a goal is achieved or a required document approved (Collins \& Block, 2007). However, owing to increasing internationalization, this tradition has lost some of its importance; a good relationship is still vital for finalizing a contract but is no longer the sole deciding factor (Phillips \& Shain, 2013).

\section{Time}

Slow progress or sudden delays in the negotiation process are often a result of circumstances embedded in Chinese culture and context. First, there is the contemporary business context that is full of procedural unpredictability, an overabundance and disarray of the regulatory framework, and occasional government interference. In addition, Confucian tradition emphasizes interpersonal trust and, consequently, the need to invest time and energy in relationship building between the two counterparts. Furthermore, a more hierarchical organization coupled with the communitarian nature of the Chinese people results in an unfamiliar (to Western negotiators), "extensive" need to consult superiors during the negotiation process, as well as to reconcile any disagreement within the Chinese negotiating party during the decision-making process. All these factors can result in frequent interruptions and delays (Tian, 2016, Miles, 2003; Phillips \& Shain, 2013).

This complicates decision-making and often frustrates European managers who are used to working in a more individualistic culture (Graham \& Lam, 2003; Hofstede, 2016). 
Furthermore, groups require time to get to know each other (Hofstede, 2016; Sebenius \& Qian, 2008). Exerting pressure is not recommended because it is an indicator of potential problems in one's company and it might also be viewed as a signal to close the negotiation and settle for a lower timespan of commitment (Miles, 2003).

Slow progress, interruptions, and delays, however, can also be part of a ploy to take advantage of time pressures of the other negotiation party. Stratagem No. 4 of the 36 Stratagems: "Awaiting at one's ease the exhausted enemy," and from Sun Tzu's "The Art of War": "Control the enemy and don't let yourself be controlled by them" recommend exploiting Chinese patience in the face of European impatience (von Senger, 2004; Tian, 2016; Pye, 1992). To the Chinese businessmen, most foreigners seem to be in a hurry to finalize an agreement, so the Chinese negotiators gain an advantage by slowing down the pace. Time manipulation can also work the other way in that the Chinese rush the other party into making concessions by applying time pressure (Collins \& Block, 2007).

\section{Hospitality}

Hospitality transcends from Confucian cultural tradition to after-hours time spent together to build relationships. In former times, Chinese negotiators were famous for showing great hospitality to negotiators from abroad. Hospitality towards guests from afar is an important rule in the Confucian concept of propriety. It is also a necessity in business dealings. In the absence of a reliable rule of law, warm hospitality deepens personal relationships which traditionally form the foundation of a stable working arrangement (IOE, 2010, Tian, 2016). It is with this aim that work and social life are not two separate things in China but belong together. Many business deals are sealed outside working hours. Often banquets are heldfrequently including drinks and festivities. Tea houses or KTV (Karaoke Television) entertainment centers are popular too. The environment is more informal, and even if an agreement is not signed at the social event, it might be supportive of closing the deal (IOE, 2010). At social events such as banquets, where the two parties get to know each other better, questions may be asked that are considered intrusive from a European perspective, such as age, income, or marital status. This is not meant to offend, but rather to strengthen a relationship given the long-term commitment envisaged (IOE, 2010, Sebenius \& Qian, 2008). In this sense, informal, outside-work activities are used to strengthen interpersonal relationships, and thus enhance cooperation.

These leisure activities, however, can also serve a hidden agenda: to lull negotiation partners into complacency, distract or exhaust them physically, or impair their alertness, concentration, and resolve at the negotiation table by offering them too much alcohol and food, and too little sleep. Stratagem No. 10 of the 36 Stratagems recommends hiding the dagger behind a smile, suggesting that evil intentions can be hidden by outward friendliness (Senger, 2004). Drinking together as a form of social bonding can also be used to get visitors inebriated. From a tactical point of view, hospitality can be used to tire out the other party or get them to drink too much the night before negotiations, resulting in a 
hangover the following morning and leaving the Chinese in a favorable position (Fang, 2006, Collins \& Block, 2007, Tian, 2016). The same activities perceived as a token of appreciation and hospitality can conceal malevolent intentions.

\section{Neutral and Affective Communication}

Apparently, there are vast cultural differences when it comes to communication style. Some cultures practice authenticity, transparency, and self-expression and, consequently, have an open and frequently emotional communication style. Confucian tradition emphasizes personal restraint in the interest of sustaining group harmony and consequently advocates a more indirect, measured, and neutral communication style. Reserved and cautious communication is considered a sign of maturity, self-restraint, and respect towards others (Hall, 1976; Gudykunst et al., 1996). Open and direct communication that includes negative emotional connotations can appear very confrontational and combative. Disregarding the Confucian moral code or openly questioning or criticizing someone is disastrous in Chinese society because it destroys harmony and thus weakens one's own prestige and public standing, which eventually leads to a loss of face on both sides (Sebenius \& Qian, 2008; IOE, 2010; Phillips \& Shain, 2013). Even in modern China, this cultural tendency to retain a neutral face in public still prevails, especially in a professional, working environment.

People unfamiliar with Confucian communication etiquette may misinterpret this as a lack of interest or enthusiasm, or worse still as being dishonest or insincere. In a further twist, such disparities in communication style may be used by the Chinese side as a means to irritate, confuse, or trick their negotiation partners. Applied as a tactic, showing or feigning anger or frustration can serve as a tool of intimidation by suggesting great disappointment and a corresponding need for compensation (Collins \& Block, 2007). Stratagem No. 27 of the 36 Stratagems recommends: "Feigning madness without losing the balance" proposes the amplification or reduction of emotional expression to exasperate an opponent.

\section{Red Tape, Ambiguous Rules and Regulations}

Owing to the need to conform to international business and trade rules, the Chinese have amended and adjusted their own rules and regulations.

Politics and bureaucracy play a significant role in the Chinese business environment. Specific directions are laid down by the government to which companies must align themselves (Miles, 2003). As for the legal framework, it is mandatory to know and comply with given rules and regulations (Ambler et al., 2008; Sebenius \& Qian, 2008; Phillips \& Shain, 2013). In practise, however, inflexible bureaucracy, long waiting times, complex, opaque, and contradictory rules and regulations, inexplicable delays in the issuing of permits and incidents of intellectual property theft often occur and represent obstacles, inconveniences, and risks that foreign companies face when doing business in China (Phillips \& Shain, 2013; Ghauri \& Fang, 2000). 
When being confronted with such, it is crucial to know whether one has an integrative Chinese negotiation counterpart who speaks the truth and sincerely aims for a mutually beneficial solution of these obstacles or whether one has to prepare for a distributive approach on the Chinese side. Although these problems can be the modus operandi in China, for which the Chinese negotiation party cannot be held responsible, there is a possibility that the Chinese are overemphasizing or even fabricating red tape and legal requirements as leverage to gain an advantage. Stratagem No. 3 of the 36 Stratagems advises to "kill with a borrowed knife," i.e., keep the real agent unidentified and try to achieve the objective by the ingenious use of a third party (the "borrowed knife") (von Senger, 2004).

So, if a Chinese counterpart blames a third party (such as the government, rules and regulations, or bureaucracy), the person may well be exploiting these annoying, yet unavoidable circumstances as a "borrowed knife" to gain maximum advantage.

Driven by the cultural traits described above, we can conclude that the Chinese negotiate from both distributive and integrative bargaining positions. Chinese negotiators can be warm and friendly hosts, often anxiously helpful partners, and eager to cooperate and make their guests feel at ease. However, they can also be tough, resourceful, and even deceitful bargainers. What can be considered a treat might turn out to be a trap. In our research we want to investigate whether the nature of interpersonal relationship can serve as a compass for distinguishing the one from another and thereby help negotiators to navigate successfully the ambiguities resulting from these opposing positions.

\section{Methodology}

Our theoretical conclusion leads to the following research question:

- How does relationship relevance influence the choice of negotiation style of the Chinese?

The following questions support the main research question:

- How can high and low relationship relevance be characterized?

- How can the Confucianist and strategist negotiating styles along with the topics time, hospitality, neutral and affective communication, as well as rules and regulations be characterized?

We investigated the research and support questions by conducting in-depth interviews about respondent experiences and interpretation of their Chinese counterparts' negotiating style and behavior. The semi-structured questionnaire started with a broad, general question and was later narrowed down to the more specific topics of time, hospitality, 
neutral and affective communication, and rules and regulations. In addition, we added a question related to relationship relevance to investigate our research question.

\subsection{Sample}

Between December 2016 and April 2017, ten interview partners (Seven Swiss, one Norwegian, two Italians, one Austrian) were selected from the business (software development, fashion, aviation, and optical industries), research (environmental protection and human development), and foreign service communities. All our interviewees have extensive, first-hand experience of regular negotiation with Chinese counterparts ranging from 10-25 years of experience (with the exception of the diplomat who served 3 years in China) involving projects such as joint ventures, setting up factories, securing new distribution channels, conducting field research, or negotiating bilateral trade agreements.

Table 1 | Anonymized interview partner list

\begin{tabular}{|c|c|c|c|}
\hline & Industry / Profession & Duration & Date \\
\hline 1 & Diplomacy, UN Ambassador & $50 \mathrm{~min}$ & 05.10 .2017 \\
\hline 2 & $\begin{array}{l}\text { Optical industry, Marketing and Sales manager } \\
\text { Asia }\end{array}$ & $1 \mathrm{~h} 45 \mathrm{~min}$ & 05.04 .2017 \\
\hline 3 & $\begin{array}{l}\text { State Export Promotion Organization, } \\
\text { Consultant }\end{array}$ & $45 \mathrm{~min}$ & 04.29 .2017 \\
\hline 4 & Automotive industry, Company owner & 1h $20 \mathrm{~min}$ & 04.27 .2017 \\
\hline 5 & NGO, Poverty reduction, Consultant & $1 \mathrm{~h} 20 \mathrm{~min}$ & 04.20 .2017 \\
\hline 6 & $\begin{array}{l}\text { NGO, Environmental protection, Managing } \\
\text { director }\end{array}$ & $2 \mathrm{~h}$ & 04.25 .2017 \\
\hline 7 & $\begin{array}{l}\text { Information technology industry, Marketing } \\
\text { Manager and Business Development Manager }\end{array}$ & 1h $35 \mathrm{~min}$ & 12.04 .2017 \\
\hline 8 & $\begin{array}{l}\text { University, Researcher urbanization Xinjiang } \\
\text { province }\end{array}$ & $2 \mathrm{~h} 20 \mathrm{~min}$ & 07.04 .2017 \\
\hline 9 & Optical industry, Managing Director & $2 \mathrm{~h} 10 \mathrm{~min}$ & 08.06.2017 \\
\hline 10 & Energy industry, Area Sales Manager & 1h $30 \mathrm{~min}$. & 08.06.2017 \\
\hline
\end{tabular}

Source: Own elaboration

The interviewees received the questionnaire in advance. The interviews followed a standardized procedure, which lasted around 45-60 minutes, were tape-recorded and transcribed. Full anonymity was guaranteed in the hope of eliciting truthful, candid responses.

\subsection{Analysis}

To analyze the transcripts, we applied the method of qualitative content analysis (Mayring, 2000) with the aim of interpreting statements and subtleties within the context of the respondents. Categories were constructed deductively based on the theoretical framework and relationship relevance. Derived from the theory and based on the research question, 
relationship relevance was defined as the importance attributed to relationship quality and expressed by the interviewee as necessary for attending social activities, finalizing contracts, achieving goals, and exchanging gifts, etc. We refined the categories by working manually through a section of the interviews and finalized them after a second complete review of all the transcripts (for coding table, see Appendix Table 1).

Following the coding procedure, we divided the transcripts into high relationship relevance (Group 1) and low relationship relevance (Group 2) Also,the four topics for each relationship group were characterized. We elaborate on our findings in the following section.

\section{Findings and Discussion}

\subsection{Relationship}

When asked whether investing in relationships was highly relevant to success in negotiations the importance of a strong interpersonal relationship and relationship network inclusion for negotiations with the Chinese was affirmed:

- $\quad$ "Yes, I believe it is crucial. Many businesses in China prefer negotiating with someone they know well rather than with an unfamiliar partner. However, this confidence is difficult to win and not given easily."

- "In contrast to the West, in China the partner is not trustworthy until proven otherwise. Confidence has to be earned. Building trust and a network are needed when signing contracts."

- "A basis of trust aids negotiations and work substantially."

- $\quad$ "Relationships are important. Recommendations from other trusted people help immensely because it is much easier to achieve something when a foundation of trust has already been established through personal recommendation."

Comments emphasizing the importance of "mutual respect", "face to face negotiations [instead of written communication], "good atmosphere" as well as the consciousness that investing in relationship-building is "time consuming but leads to better results", indicate a strong orientation towards relationship building as an obligatory necessity to conduct negotiations and work successfully. The experience of the advantages of a good relationship basis that goes beyond the actual project at stake (see the last quote above) emphasizes the importance of relationship building and network inclusion as a building block when negotiating in China.

As for the quality of the relationship the answer patterns ranged from "personal friendship" to a more functional understanding of relationship: 
- "Building trust and personal friendship takes time and requires investing in relationship building. It is, however, worthwhile in many ways to have a friend."

- "I can recommend investing in relationship building. A personal relationship with the locals eases the process to accomplish goals substantially."

There were also interviewees who did not give high priority to relationship building. The answer pattern ranged from little to no importance:

- "I think relationships and trust can help ease and simplify negotiations, but I don't think they are absolutely necessary."

- "Personal relationships are not really necessary to come to terms with the Chinese. They focus strongly on the business aspect of negotiations."

The impression that relationship building was of lesser importance when doing business with the Chinese mostly stemmed from his or her observation that the Chinese people themselves did not care about this:

- 'The Chinese are extremely direct and don't value the same level of personal interaction or relationship development as with people or companies from other cultures."

- $\quad$ "There is too little time or energy to invest in relationships. If you have what they want, they'll cooperate. They are very focused on the outcome of a deal and it being profitable."

Interview comments emphasizing the strong "bargaining power" of the Chinese due to the size and attractiveness of the Chinese market, the Chinese understanding of negotiations as a "struggle that needs to be won quickly and aggressively", as well as so-called "Westernization of the Chinese business culture", indicate that these interviewees considered relationship of little or no importance in modern day Chinese business environment.

\subsection{Four topics and eight interpretations}

In this section, we show our interviewees' perception, experiences and interpretations concerning the the above mentioned four topics, time, hospitality, neutral and affective communication, and the handling of practical constraints, such as red tape and intransparent and ambiguous rules and regulations. In order to answer our research question whether the relationship relevance influences the Chinese negotiation style we divided the experiences and interpretations of our interviewees along the categories high relationship relevance (Group 1) versus low relationship relevance (Group 2). 


\section{Topic 1: Difference in Time Management}

Are slow progress and sudden delays in the negotiation process the result of procedural unpredictability, of an overabundance and disarray of the regulatory framework, and occasional government interference; is it a result of Confucianism based hierarchy and harmony orientation; or is it a ploy to take advantage of time pressures of the other negotiation party - in line with the stratagem "Awaiting at one's ease the exhausted enemy"?

When asked if they had experienced delays during negotiations with the Chinese, answers ranged from "yes, this certainly happens" and "this happens a lot" to "there is no point in pressing the matter." In response to the question whether they suspected the delay was a tactical move on the part of the Chinese or the result of business culture and contextual circumstances, there were statements that pressure of time was used by the Chinese as leverage for getting better terms.

Grouping the answers along the high relationship relevance (Group 1) versus low relationship relevance (Group 2) divide, the following experiences can be found:

\section{High relationship relevance (Group 1)}

- [Experienced negotiations prolonged or drawn out for too long?] "Did not experience such a thing."

- "The signing process might take a while because consultations with superiors may be necessary."

- "The delay was usually caused by the need to wait for the approval of a more highly ranked person."

- "This can happen due to the necessity to consult superiors or for tactical reasons."

- $\quad$ "If your firm is under time pressure, negotiations are going to be delayed. This can have negative consequences for the Western company if they are not careful. If there is a deadline for achieving an outcome, delaying talks to achieve concessions and improve your negotiating position is a valid strategy."

\section{Low relationship relevance (Group 2)}

- [Experienced negotiations prolonged or drawn out for too long?] "Absolutely. If they see that you are in a hurry and under pressure to clinch a deal, they have no problem dragging out the process to gain some additional benefit."

- “It's a common tactic to delay most negotiations." 
- "If they realized that we were under time pressure, I had the feeling that they delay the business talks so that we conceded to higher prices."

\section{Topic 2: Chinese Hospitality}

When asked whether there had been festivities, dinner, or drinks before, during, or after negotiations, it was stated that not much time is "wasted" on such things anymore. The Chinese have become "Westernized" and in this sense get to the point immediately, even more so now since President Xi Jinping's recent anti-corruption campaign. However, it was also stated that Chinese hospitality is still offered in the form of banquets, festivities, and drinks ("barely any partnership is formed without group dinners"). Although occurring on a smaller scale than in the past, these outside work, socializing events, so their experience, were still an essential part of the negotiation process.

- "Spending time together in a more informal setting, such as at banquets and festivities, creates better terms for negotiation."

- "Festivities and banquets help us get to know each other better, leading to increased mutual trust. This can have a positive effect on negotiations for both sides and help to finalize deals."

As to the Chinese counterpart's motive behind such activities the answer pattern of both relationship relevance groups clearly differ from each other:

\section{$\underline{\text { High relationship relevance (Group 1) }}$}

- "Eating and drinking together are very helpful to build relationships. To drink together means belonging to the group, so it is suggested to accept this offer of group inclusion and to partake in these collective activities."

- "Banquets are the place where contracts are agreed. Of course, no details are discussed or contracts signed. But the decision to form the partnerships is made in this informal setting. The informality creates closeness which they need to trust you and subsequently to work things out with you."

\section{$\underline{\text { Low relationship relevance (Group 2) }}$}

- "The pressure to participate in informal, after-work activities can be a nuisance and may result in nothing more than exhaustion."

- "Despite the informality and leisurely atmosphere during these gatherings, you have to be on your guard not be indiscreet since this can be used against you during subsequent negotiations." 


\section{Topic 3: Neutral and Affective Communication Style}

In answer to the questions: "Have you experienced any kind of communication style anomalies during the negotiation process?" and "Have you experienced manipulation of the negotiation environment through extreme neutral (e.g., no facial expression, frequent verbal communication stops, and long periods of silence) or extreme affective communication behavior (e.g. sudden emotional outbursts, loud verbal communication in Chinese between themselves, use of emotive words such as "disappointed" or "impossible!" etc.)?" the generally neutral nature of the Chinese communication style was mentioned.

- "They are reserved and don't show much emotion."

- "Emotional outbursts are practically non-existent."

- "Anger and frustration are expressed seldom because it could endanger their position."

- "They are calm, but sometimes they argue intensely. This may be interpreted as being emotional but I think this is their way of doing things."

In the group with low relationship relevance (Group 2) there were reports of "faked" emotional outbursts by the Chinese as a mean to irritate or even manipulate:

- "They use emotion to manipulate the outcome of negotiations."

- "They can be very friendly and warm but, depending on the situation, also cruel or angry to gain some advantage."

- "In negotiations, the Chinese are more likely to show discontent than happiness."

- "Displaying discontent but not happiness can be employed as a tactic to get the other side party to make concessions."

- "By showing anger and discontent, an atmosphere is created in which the Chinese have to be placated."

\section{Topic 4: Red Tape, Rules, and Regulations}

Statements confirmed the experience of excessive bureaucracy and over-regulation as well as legal compliance demands that were highly disadvantageous.

- "Yes, there are indeed many restrictions."

- “This [unexpected additional legal compliance demands] certainly does occur.” 
Such incidents are not fabricated, nevertheless, some of them are being used as an excuse for not addressing the needs of the negotiation counterpart or as a bargaining advantage to force the other side to concessions. However, there is also room to maneuver. There might be loopholes and some margins of discretion. The Chinese can either follow the rules to the letter or be more accommodating and creative in finding solutions that would help overcome obstacles. A good personal relationship does not always guarantee an integrative negotiation approach on the Chinese side. Nevertheless, similar to the other topics mentioned above, for red tape, rules, and regulations the answers as per the relationship divide were:

\section{$\underline{\text { High relationship relevance (Group 1) }}$}

- "In my field, many things are conducted informally and regulations or laws never posed any difficulties for our collaboration."

- "A basis of trust aids negotiations and work substantially. They helped me to find a way to work around the obstacles."

- "We had a trustworthy negotiation partner. With his help we could overcome many obstacles since he knew the rules and customs."

- "A personal relationship with the Chinese counterpart eases the process to accomplish goals substantially because loopholes exist but the willingness to use them is, without a good relationship, rather unlikely."

\section{Low relationship relevance (Group 2)}

- "To set up a company in China, you need to hand over 51\% ownership of the subsidiary to a Chinese firm. In this sense China is very protectionist. Since the Chinese are ardent competitors, they take advantage of the joint venture rule to edge Western manufacturers out. We will lose the global competition if we do not remain driven to innovate."

- $\quad$ "For them [the Chinese negotiation counterpart] the rules are often an excuse to get a better bargain. They pitch a price for the resolution of regulative, bureaucratic obstacles."

\subsection{Summary and Discussion of Findings}

There were respondents who affirmed the importance of a good interpersonal relationship and relationship network inclusion when negotiating with the Chinese. There were also respondents who did not place a high priority on relationship building. A closer look at the four topics reveals the summarized tendencies for each group. 
In respect of time, the answers suggest a tendency that relationship influences the way Chinese negotiation behavior is interpreted. A strong relationship results in the experience of time delays as primarily the result of a Chinese hierarchical structure that often requires consultation with superiors before contracts are signed. Tactical considerations are not excluded (see the two last responses in Group 1), but they occur in a more general sense. In contrast, Group 2 respondents perceived time delays as a tactic by the Chinese to put pressure on them according to the spirit of Stratagem No. 4 of the 36 Stratagems: "Awaiting at one's ease the exhausted enemy."

With regard to hospitality, Group 1 experienced Chinese invitations to banquets, festivities, and drinks as genuine effort to establish a personal relationship and group inclusion so as to create mutual trust - both of which are indispensable for business cooperation. Group 2 experienced such social activities as a necessary, but not wholly enjoyable, aspect of Chinese tradition. The reluctance to participate in such events was articulated. A hidden, dubious agenda by the Chinese such as wearing down opponents or placing them in a compromising situation might be suspected - entirely in line with Stratagem No. 10 of the 36 Stratagems: "Hiding the dagger behind a smile."

When considering the use of emotion in communication, there is a perception of the Chinese as emotionally neutral. Nevertheless, in contrast with the usual emotional restraint encounters with the Chinese, there are reports of Group 2 of a deliberate use of emotions to influence the outcome of negotiations. Such a tactic follows the advice given in Stratagem No. 27 of the 36 Stratagems: "Feigning madness without losing the balance."

The relationship divide was also evident in the use of red tape as well as rules and regulations. The group with high relationship relevance (Group 1) viewed this as a facilitator in the face of difficulties, while Group 2 felt that the regulatory environment was being used to achieve desired goals in line with Stratagem No. 3 of the 36 Stratagems: "Kill with a borrowed knife."

The examination of the answer patterns of the four topics deducted from the most prominently discussed aspects in the context of negotiation. We can answer our research question in the following way: Members of Group 1 experienced a more cooperative Chinese negotiation behavior. Generally speaking, difficulties, obstacles, or problems were openly and truthfully communicated by the Chinese side, and their Chinese counterparts appeared genuinely willing to overcome these issues.

Group 2's benevolent perception was in line with their experience. Generally, members of Group 1 also experienced less deceit, more proactive support, greater flexibility, and a willingness to overcome red tape and unhelpful rules and regulations - in short, integrative bargaining behavior by the Chinese. Their long-term experiences made them conclude that relationship-building was worth the time and effort. For some, the advantages of a good relationship went even beyond the actual project being discussed and has proven to be of 
great benefit in other projects thanks to the negotiator's access to a broader relationship network. Suspicion and deceit were experienced by Group 2, whose dealings with the Chinese generally ceased following the end of the project in question.

A schematic overview of the findings is presented in Figure 1.

Figure 1 | Extension of Chinese integrative and distributive negotiation with relationship relevance

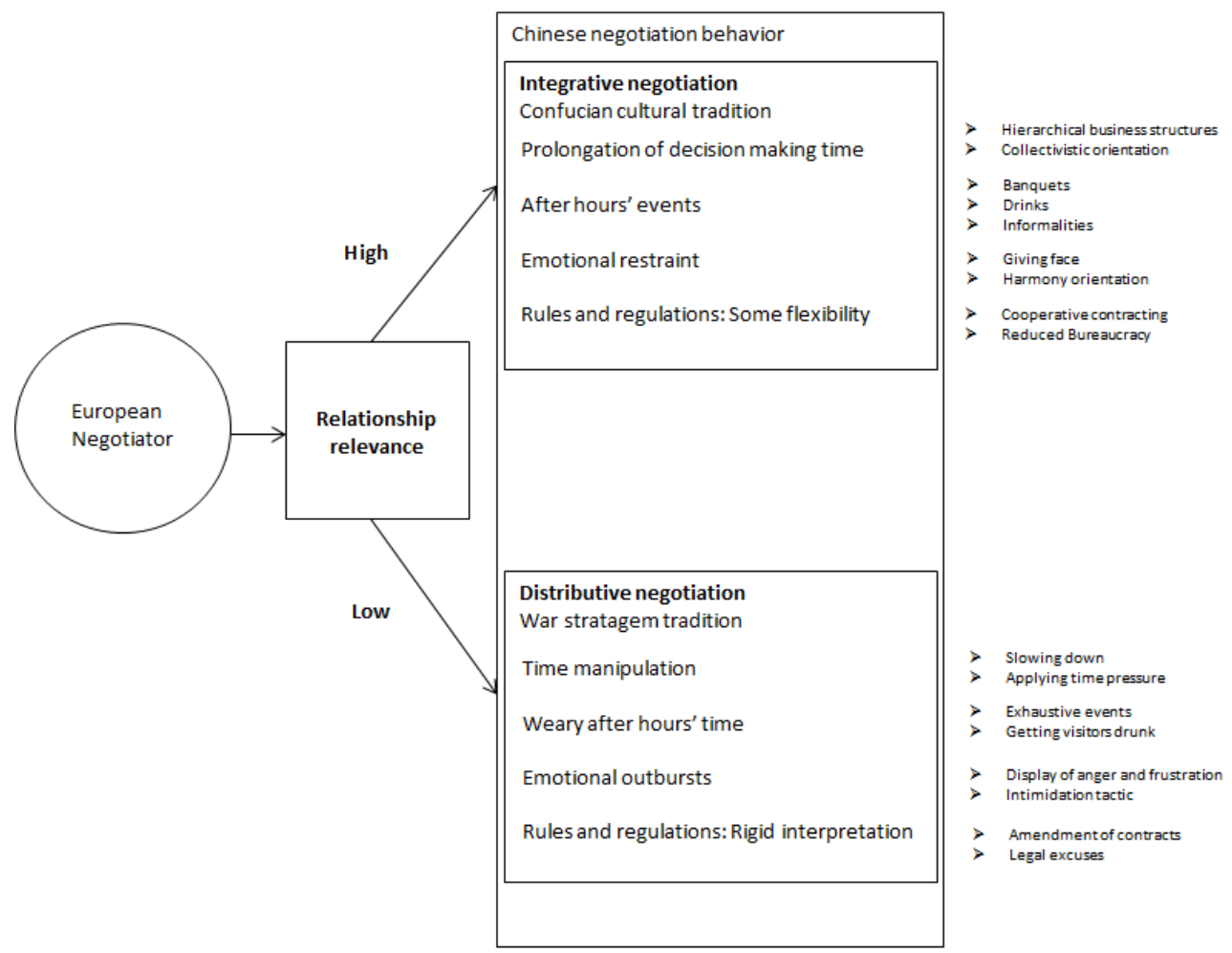

Source: Own elaboration

\section{Conclusion}

When negotiating in China, two opposing styles can be encountered The "soft" Confucian who is interested in a long-term business relationship that is reciprocal and cooperative, and the "hard" tactician who views the negotiating table as a battlefield and contest of wits.

A sudden slowdown in the midst of the negotiation process can stem from the Confucian tradition of lengthy decision-making, or it may be part of a clever ploy to take advantage of the time pressures often faced by European managers. Chinese hospitality in the form of 
banquets and other after-hours activities can indeed be part of a relationship-building ritual. However, its real purpose might also be to lull the negotiation partner into complacency through distraction or physical exhaustion. Emotions displayed in a negotiation setting can be genuine or serve as a means of manipulation. The claim of regulatory and bureaucratic obstruction and delay can be valid, but it may also be fabricated or embellished by the Chinese to sway the outcome. The navigation of these ambiguities requires skill in analyzing and interpreting the situation correctly. When negotiating in China, the challenge is to avoid falling into a carefully laid trap while simultaneously respecting Chinese traditions and culture.

The distinction between integrative and distributive negotiation tactics has a long tradition in the theoretical literature covering negotiating styles and is well established in business applications. It is our understanding that when negotiating with the Chinese, this should not be viewed as a rigid world of opposites. "Soft" and "hard" tactics might represent the poles of a continuum, but negotiations take place in an ambiguous world. Our findings contribute to research in the field of relationship and negotiation by revealing that managers who consider relationship building as less relevant may well encounter a more distributive negotiation style, whereas those who attribute high importance to relationshipbuilding experience a more integrative negotiation style. Our interview partners seemed well aware of the circumstances in which negotiations take place, and do not seem caught by surprise. Given their long-term China experience, this could be expected. A shrewd negotiator will be prepared for either situation; however, we recommend attempting to establish a relationship because this facilitates negotiation and tends to result in a more integrative negotiation style on the part of the Chinese.

The ten interviewees gave us their insight on their negotiation experience in China in general and the influence of high relationship relevance to the Chinese negotiation style in particular. Our study provides a starting point for testing the link between relationship quality and the Chinese choice of negotiation style quantitatively.

This study also offers guidance for European managers doing business in China by deepening their understanding of the cultural roots of Chinese negotiation tactic, by giving advice on how to anticipate and identify deceitful behavior, and by offering recommendations on how to counteract the distributive negotiation approach of the Chinese.

\section{References}

Ambler, T., Witzel, M., \& Xi, C. (2008). Doing Business in China. Taylor \& Francis. Butler, J.K., Jr. (1999). Trust expectations, information sharing, climate of trust, and negotiation effectiveness and efficiency. Group \& Organization Management, 24(2), 217-238. 
Buttery, E. A., \& Leung, T. K .P. (1998). The difference between Chinese and Western negotiations. European Journal of Marketing, 32(3/4), 374-389.

Cheng, J., Huang, Y., \& Su Y. (2017). Relationality in negotiations: A systematic review and proposition for future research. International Journal of Conflict Management, 28(3), 295-321.

Collins, R., \& Block, C. (2007). Doing Business in China For Dummies. Indianapolis: Wiley Publishing Inc.

De Cremer, D. (2015). Understanding Trust, in China and the West. Harvard Business Review. Retrieved March 30, 2018 from https://hbr.org/2015/02/understandingtrust-in-china-and-the-west.

Fang, T. (1999). Chinese Business Negotiation Style. Thousand Oaks, CA: Sage Publications.

Fang, T. (2006). Negotiation: The Chinese Style. Journal of Business \& Industrial Marketing, 21(1), 50-60.

Gunia, B. C., Brett, J. M., Nandkeolyar, A. K., \& Kamdar, D. (2011). Paying a price: Culture, trust, and negotiation consequences. Journal of Applied Psychology, 96(4), 774-89.

Ghauri, P., \& Fang, T. (2001). Negotiating with the Chinese: A socio-cultural analysis. Journal of World Business, 36(3), 303-325.

Graham, J. L., \& Lam, N. M. (2003). The Chinese negotiation. Harvard Business Review, 81(10), 82-91.

Gudykunst, W. B., Matsumoto, Y., Ting-Toomey, S., Nishida, T., Kim, K., \& Heyman, S. (1996). The influence of cultural individualism-collectivism, self-construals, and individual values on communication styles across cultures. Human Communication Research, 22(4), 510-543.

Hall, E. T. (1976). Beyond culture. Garden City, NY: Doubleday.

Hofstede Insights (2016). Compare Countries. Retrieved May 22, 2018 from https://www.hofstede-insights.com/product/compare-countries/.

IOE Institute of Exports (2010). Doing business in China. Retrieved April 27, 2018 from http://www.china.doingbusinessguide.co.uk.

Kong. D. T., Dirks, K. T., \& Ferrin, D. L. (2014). Interpersonal Trust within negotiations: Meta-analytic evidence, critical contingencies, and directions for future research. Academy of Management Journal, 57(5), 1235-1255.

Krippendorff, K. (2003). The art of the advantage: 36 strategies to seize the competitive edge. London: Penguin Group.

Lax, D., \& Sebenius, J. K. (1986). The Manager as Negotiator: Bargaining for Cooperation and Competitive Gain. New York: Free Pres.

Leung, T. K. P., Chan, R. Y. K., Lai, K. H., \& Ngai, E. W. T. (2001). An Examination of the Influence of Guanxi and Xinyong on Negotiation Outcome in China: An old friend approach. Industrial Marketing Management, 40, 1193-1205.

Lewicki, R. J., Saunders, D. M., \& Barry, B. (2015). Negotiation. Boston: McGraw-Hill Education. 
Lewicki, R. J., \& Bunker, B. B. (1995). Trust in Relationships. A model of development and decline. In Conflict, cooperation, and justice: Essays inspired by the work of Morton Deutsch (pp. 133-173). San Francisco: Jossey-Bass.

Miles, M. (2003). Negotiating With the Chinese. Journal of Applied Behavioral Science, 39(4), 453-472.

Mayring, P. (2000). Qualitative Content Analysis. Forum: Qualitative Social Research, 1(2), Art. 20. Retrieved from http://www.qualitativeresearch.net/index.php/fqs/article/view/1089/2385

Murninghan, J. K., Babcock, L., Thompson, L., \& Pillutla, M. (1999). The information dilemma in negotiations: Effects of experience, incentives and integrative potential. International Journal of Conflict management, 10(4), 313-339.

Phatak, A. V., \& Habib, M. M. (1996). The dynamics of international business negotiations. Business Horizons, 39(3), 30-38.

Phillips, P., \& Shain, J. (2013). Chinese Negotiation. Business Conflict Management LLC. Retrieved from http://www.businessconflictmanagement.com/blog/2013/05/

Pye, L. W. (1992). The Chinese approach to negotiating. Thunderbird International Business Review, 34(6), 463-468.

Salacuse, J. (2003). The global negotiator. Making, Managing, and mending deals around the world in the twenty-first century. London: Palgrave Macmillan.

Salacuse, J. (2004). Negotiating: The top ten ways that culture can affect your negotiation. Ivey Business Journal, 69(1), 1-6.

Sebenius, J. K., \& Qian, J. (2008). Cultural notes on Chinese negotiating behavior. Cambridge, MA: Harvard Business School.

Seligman, S. D. (1999). Chinese Business Etiquette. A Guide to Protocol, Manners, and Culture in the People's Republic of China. New York: Warner Business Books.

Senger, H. v. (2004). The 36 Stratagems of Business. Munich: Carl Hanser Verlag.

Sun Tzu (2009). The Art of War. Translated by M. A. Lionel Giles. Pax Librorum.

Triandis, H. C. et al. (2001). Culture and deception in business negotiations: A multilevel analysis. International Journal of Cross-cultural Management, 1(1), 73-90.

Tian, X. (2016). Managing International Business in China. Cambridge: Cambridge University Press.

Walton, R. E., \& McKersie, R. B. (1965). A behavioral theory of labor negotiations: An analysis of a social interaction system. New York: McGraw-Hill.

Vanhonacker, W. R. (2004). Guanxi networks in China. The China Business Review, 31(3), 48-53.

Zhang, J. D., Leigh, A. L., \& Wu, L. (2015). Deception in Negotiation: Culturally Divergent Effects. Management and Organization Review, 11(1), 123-144. 


\section{Authors}

Petra Y. Barthelmess

Head International Education

Department International Business

Zurich University of Applied Sciences

School of Management and Law

Zurich, Switzerland

petra.barthelmess@zhaw.ch

\section{Patricia Enzmann}

Senior Project Manager at the Center for Asia Business

Department International Business

Zurich University of Applied Sciences

School of Management and Law

Zurich, Switzerland

patricia.enzmann@zhaw.ch

\section{Michael Settelen}

Lecturer/Research Associate at the Center for Asia Business

Department International Business

Zurich University of Applied Sciences

School of Management and Law

Zurich, Switzerland

michael.settelen@zhaw.ch

\section{Nicolas Schärmeli}

BSc International Management graduate

Zurich University of Applied Sciences

School of Management and Law

Zurich, Switzerland

schaeni1@students.zhaw.ch 


\section{Appendix:}

Coding categories

\begin{tabular}{|c|c|c|c|c|c|}
\hline Category & $\begin{array}{l}\text { Negotiation } \\
\text { behavior }\end{array}$ & Definition & Authors & Example & Coding Rule \\
\hline $\begin{array}{l}\text { Relationship } \\
\text { relevance }\end{array}$ & & $\begin{array}{l}\text { Importance attributed to relationship quality. } \\
\text { Expressed as necessity to e.g.: } \\
\text { - } \quad \text { attend social activities } \\
\text { - } \quad \text { finalize contracts } \\
\text { - } \quad \text { achieve goals } \\
\end{array}$ & $\begin{array}{l}\text { Sebenius \& Qian } \\
(2008) \\
\text { Collins \& Block (2007) }\end{array}$ & $\begin{array}{l}\text { "Relationships are } \\
\text { important." }\end{array}$ & $\begin{array}{l}\text { At least one aspect has to be } \\
\text { mentioned to indicate high } \\
\text { importance otherwise low. }\end{array}$ \\
\hline \multirow{2}{*}{ Time } & $\begin{array}{l}\text { Confucian } \\
\text { cultural } \\
\text { tradition }\end{array}$ & $\begin{array}{l}\text { Prolongation of time needed for decision } \\
\text { making in negotiations due to: } \\
\text { - } \quad \text { Hierarchical business structures } \\
\text { - } \quad \text { Collectivistic orientation }\end{array}$ & $\begin{array}{l}\text { Graham \& Lam (2003) } \\
\text { Hofstede (2016) } \\
\text { Miles (2003) } \\
\text { Phillips \& Shain (2013) } \\
\text { Sebenius \& Qian } \\
(2008)\end{array}$ & $\begin{array}{l}\text { "The signing process might } \\
\text { take a while because } \\
\text { consultations with superiors } \\
\text { may be necessary." }\end{array}$ & Mentioning of one of the aspects \\
\hline & Tactic & $\begin{array}{l}\text { Manipulation of time available for } \\
\text { negotiations by: } \\
\text { - } \quad \text { Slowing down } \\
\text { - } \quad \text { Applying time pressure }\end{array}$ & Collins \& Block (2007) & $\begin{array}{l}\text { "If they see that you are in a } \\
\text { hurry and under pressure to } \\
\text { clinch a deal, they have no } \\
\text { problem dragging out the } \\
\text { process to gain some } \\
\text { additional benefit." }\end{array}$ & Mentioning of one of the aspects \\
\hline \multirow[b]{2}{*}{ Hospitality } & $\begin{array}{l}\text { Confucian } \\
\text { cultural } \\
\text { tradition }\end{array}$ & $\begin{array}{l}\text { Hospitality and "after hours' time" spent } \\
\text { together involving e.g.: } \\
\text { - } \quad \text { Banquets } \\
\text { - } \quad \text { Drinks } \\
\text { - } \quad \text { Informalities } \\
\end{array}$ & IOE (2010) & $\begin{array}{l}\text { "This is an essential part of } \\
\text { Chinese culture and often } \\
\text { the basis on which } \\
\text { relationship is built." }\end{array}$ & Mentioning of one of the aspects \\
\hline & Tactic & $\begin{array}{l}\text { Hospitality and "after hours' time" used } \\
\text { wearing the other party: } \\
\text { - } \quad \text { Exhaustive events } \\
\text { - } \quad \text { Getting visitors drunk }\end{array}$ & $\begin{array}{l}\text { Collins \& Block (2007) } \\
\text { Tian (2016) }\end{array}$ & $\begin{array}{l}\text { "The pressure to participate } \\
\text { in informal, after-work } \\
\text { activities can be a nuisance } \\
\text { and may result in nothing } \\
\text { more than exhaustion." }\end{array}$ & Mentioning of one of the aspects \\
\hline
\end{tabular}




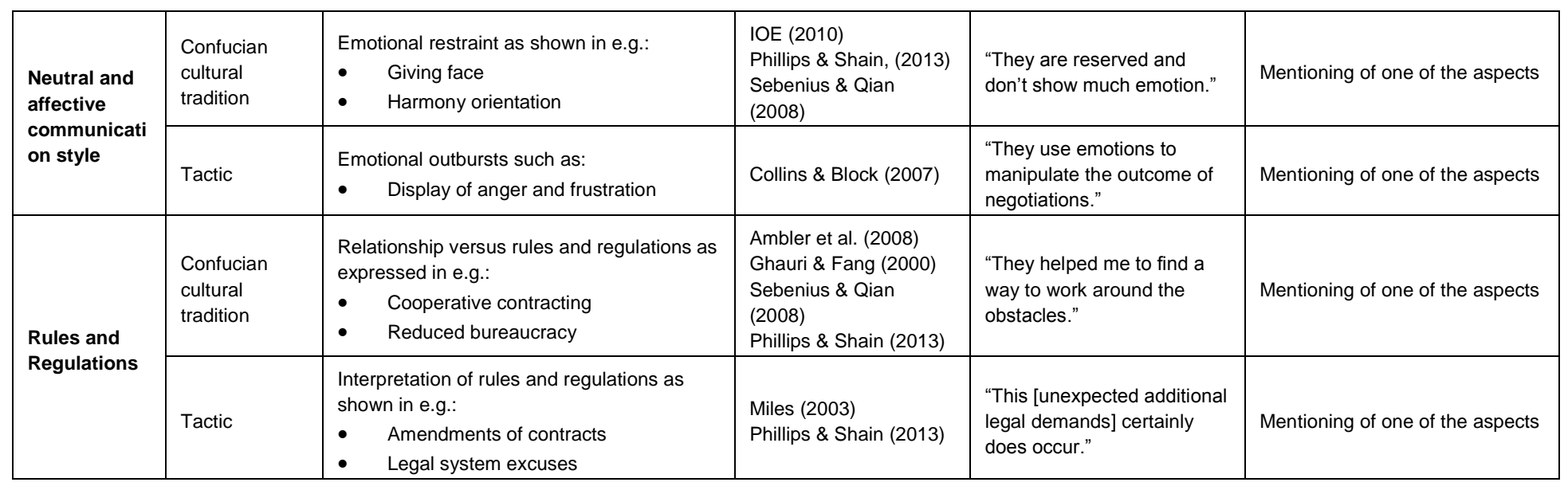

